\title{
A casa como espaço do cuidado: as práticas em saúde de Agentes Comunitários de Saúde em Montes Claros (MG)
}

\author{
The house as a care space: health practices of Community Health \\ Workers in Montes Claros (MG)
}

Vagner Caminhas Santana', Luciene Burlandy', Ruben Araujo de Mattos ${ }^{\mathbf{2}}$

DOI: $10.1590 / 0103-1104201912012$

RESUMO O presente estudo teve como objetivo analisar as práticas de atenção à saúde desenvolvidas por Agentes Comunitários de Saúde (ACS), no âmbito da visita domiciliar, com famílias atendidas pela Estratégia Saúde da Família (ESF), no município de Montes Claros (MG). Estudos no campo da promoção da saúde vêm indicando que tais práticas podem assumir, por vezes, posturas mais prescritivas, disciplinares, culpabilizantes, normativas, voltadas mais diretamente para a mudança comportamental do indivíduo, ou, de forma distinta, podem ser mais dialógicas e interativas na relação com as famílias atendidas, pautadas em uma concepção de atenção integral em saúde. O presente estudo analisou as práticas dos ACS com o objetivo de compreender como eles vêm abordando aspectos da vida privada e da dimensão pública do processo em saúde e quais as distintas posturas que adotam nas interações com as famílias. Foram realizadas entrevistas semiestruturadas com usuários da ESF e ACS de três equipes, e observadas 20 visitas domiciliares realizadas pelos ACS no ano de 2013. Concluiu-se que as práticas dos ACS assumem, por vezes, características que apontam para a imposição de um saber-poder biomédico e, por outras, que consideram aspectos da subjetividade do indivíduo/comunidade.

PALAVRAS-CHAVE Agentes Comunitários de Saúde. Atenção Primária à Saúde. Promoção da Saúde. Visita Domiciliar.

ABSTRACT The present study aimed at analyzing the health care practices developed by Community Health Workers, within the scope of the home visit, with families assisted by the Family Health Strategy (FHS), in the municipality of Montes Claros $(M G)$. Studies in the field of health promotion have indicated that such practices may, sometimes, assume more prescriptive, disciplinary, guilty-apportioning, normative attitudes, aimed more directly at the behavioral change of the individual, or, in a different way, may be more dialogic and interactive in relation with families assisted, based on a concept of integral health care. The study analyzed the practices of the CHW in

1 Universidade Federal Fluminense (UFF) - Niterói (RJ), Brasil.

caminhasdokiau@hotmail.

com

2 Universidade do Estado do Rio de Janeiro (Uerj), Instituto de Medicina Social (IMS) - Rio de Janeiro (RJ), Brasil. order to understand how they have been addressing aspects of private life and the public dimension of the health process and what different postures they adopt in interactions with families. Semistructured interviews were carried out with users of FHS and CHW from three teams, and 20 home visits conducted by $\mathrm{CHW}$ were observed in the year 2013. It was concluded that the practices of $\mathrm{CHW}$, sometimes, assume characteristics that point to the imposition of a biomedical know-power and, on the other hand, that they consider aspects of the subjectivity of the individual/community.

KEYWORDS Community Health Workers. Primary Health Care. Health Promotion. Home Calls. 


\section{Introdução}

O presente estudo analisou as práticas de atenção à saúde que vêm sendo desenvolvidas por Agentes Comunitários de Saúde (ACS), no âmbito da Visita Domiciliar (VD), com famílias atendidas pela Estratégia Saúde da Família (ESF), no município de Montes Claros (MG), com o objetivo de problematizar as possíveis assimetrias de poder.

As práticas de Promoção da Saúde (PS) podem ser prescritivas, voltadas para a mudança comportamental que culpabiliza o indivíduo, ou dialógicas e pautadas em uma concepção de cuidado integral da saúde que não seja impositiva da racionalidade médica ${ }^{\mathbf{1}, \mathbf{2}}$.

Embora crescentes, são ainda escassos os estudos realizados no Brasil que problematizam a VD como um espaço potencial para a configuração de mecanismos de controle sobre a população, a imposição da racionalidade médica e o exercício do biopoder (ou biopolítica) ${ }^{3}$. Ao possibilitarem o acesso dos ACS ao espaço singular da vida privada que é o domicílio, podem se configurar relações mais ou menos assimétricas entre os agentes envolvidos.

A VD, considerada como um instrumento de trabalho ${ }^{4-7}$, mobiliza questões que envolvem diversos aspectos do processo saúde-doença da população atendida, e a formação dos profissionais para adentrar o domicílio ainda é desafiadora, pois remete às fronteiras entre os espaços público e privado. As práticas assistenciais no âmbito da VD podem borrar com esta tradicional dicotomia entre esfera pública e privada, uma vez que são exercidas por agentes públicos dentro de um ambiente privado. Por outro lado, é também neste espaço de cuidado e de escuta que manifestações plurais dos indivíduos podem ser incorporadas às práticas dos profissionais de saúde, e relações mais ou menos assimétricas podem ser estabelecidas.

Sendo assim, o presente estudo analisou as diversas configurações de práticas dos ACS no âmbito da VD, visando refletir sobre o seu potencial na construção do cuidado integral em saúde pautado em relações menos assimétricas e mais recíprocas entre os sujeitos envolvidos. Problematizou como esses agentes abordam aspectos da vida privada e da dimensão pública nas distintas práticas de cuidado em saúde que constroem, a partir das relações que estabelecem com as famílias no espaço da VD. Foi norteado pelas seguintes questões: como as práticas de saúde desenvolvidas pelos ACS consideram o contexto e a experiência dos sujeitos em relação ao seu processo saúde-doença? Suas práticas são pautadas em posturas mais centradas nas mudanças de comportamentos individuais e nos estilos de vida, em uma perspectiva integral de atenção à saúde, ou em ambas? De que forma abarcam aspectos da dimensão pública e privada do processo saúde-doença e perspectivas mais prescritivas, normativas ou dialógicas de interação com os indivíduos e famílias?

\section{Percurso teórico metodológico}

As 'práticas de cuidado' em saúde são aqui consideradas como o conjunto de práticas sociais que se constituem como esforços (ou tentativas) de assegurar a continuidade da vida de indivíduos, de um grupo social ou da espécie, e a análise recai sobre as práticas dos $\mathrm{ACS}^{\mathbf{8}}$ no âmbito da casa, espaço onde a VD se constrói e que abrange uma diversidade de outras práticas que devem ser consideradas.

As concepções sobre PS que pautam a ESF podem focar-se tanto em mudanças nos comportamentos individuais, a partir da prevenção e fatores de risco, ou no contexto socioambiental, visando à construção de ambientes saudáveis em uma lógica mais positivista de saúde ${ }^{9-11}$. O caráter normativo e medicalizante pode se configurar em ambas as direções ${ }^{12}$, e o presente estudo pressupõe que as práticas dos ACS no âmbito da VD podem ser construídas em uma perspectiva mais prescritiva/medicalizante ou dialógica. Entende-se por medicalização não o uso em si de medicamentos, mas o processo de invasão da vida social pela medicina e pelo 
saber médico que ocorreu a partir do século XIX. Neste sentido, Mattos ${ }^{\mathbf{1 2}}$ alerta para a necessidade de prudência quanto ao exercício do diagnóstico precoce, uma vez que este tipifica a medicalização ao considerar que o profissional tem sempre razão para intervir sobre os indivíduos/coletivos. A medicina preventiva acaba 'colonizando' a vida privada para dizer como o indivíduo/família deve se comportar, sugerindo 'bons comportamentos'. Não apenas trata o doente, mas também recomenda hábitos, sugere 'modos de vida saudáveis' ${ }^{13}$.

Foucault ${ }^{14}$ identifica o poder disciplinar sobre os indivíduos, que começa no corpo: a biopolítica voltada para o controle de populações por meio do gerenciamento sobre a vida, a morte e a saúde, em um dado território, que transfere responsabilidade para o indivíduo e o controla por meio da subjetivação e do autocuidado. Essa nova tecnologia de controle das populações foi possível pela supremacia do poder científico ${ }^{\mathbf{1 4}}$.

No caso das práticas de atenção em saúde dos ACS, essa questão assume especial relevância, pois tratam-se de agentes públicos que exercem suas atribuições em um espaço privilegiado de vivência da esfera privada, qual seja o domicílio. A perspectiva que se coloca não é a de romper com a medicalização em si, mas com uma medicalização colonizadora, com práticas de cuidado não emancipatórias ${ }^{8}$.

A construção de relações de cuidado menos assimétricas demanda uma reflexão sobre as práticas em contextos específicos, que possibilite identificar os movimentos na direção do controle, da tutela, e os movimentos na direção de encontros que reconheçam os sujeitos e suas práticas de cuidado.

Com base nesse referencial, este trabalho analisou como essas distintas abordagens se expressam nas práticas dos ACS, no âmbito da VD, em Montes Claros (MG). O bairro Morrinhos foi escolhido como lócus principal da pesquisa em função da sua heterogeneidade, uma vez que nele residem pessoas situadas em extratos de renda baixa e média. Foram realizadas entrevistas semiestruturadas com
10 usuários da ESF e 9 ACS das 3 equipes das Unidades Básicas de Saúde (UBS), e observadas 20 VD realizadas por ACS no ano de 2013.

Todos os ACS que participaram do estudo eram mulheres com idades entre 27 e 42 anos; todos concluíram o Ensino Médio, dois deles concluíram o curso técnico em enfermagem e um possuía curso superior completo em pedagogia.

O estudo seguiu as regulamentações descritas na Resolução no 466/2012, do Conselho Nacional de Saúde (CNS), do Ministério da Saúde, e a pesquisa foi aprovada pelo Comitê de Ética e Pesquisa do Hospital Universitário Antônio Pedro (CEP/HUAP), da Universidade Federal Fluminense, mediante o parecer $\mathrm{n}^{0} 335.685$.

\section{Resultados}

\section{O acesso do agente público ao espa- ço da vida privada}

A heterogeneidade do território estudado se expressa na divisão feita pelos próprios ACS entre o trabalho que é possível de ser realizado na área mais próxima ao centro da cidade, com melhores condições socioeconômicas e infraestrutura, e na região onde estão localizados o 'morro' e áreas circunvizinhas, onde residem as famílias de mais baixa renda e que demandam mais atendimentos.

O bairro de Morrinhos é estigmatizado como local de venda de drogas, o que gera desconforto e insegurança para os moradores e intimidação dos ACS, que evitam as VD nos horários em que o comércio de entorpecentes é maior. Em geral, os ACS procuram estabelecer uma relação de confiança e de troca com a comunidade, partilhando a 'lei do silêncio'.

Embora a ESF esteja consolidada no bairro com ampla adesão dos moradores, algumas famílias, por possuírem planos de saúde, não aceitam se cadastrar na ESF, utilizando-a somente em ações pontuais, como o aferimento de pressão. 
A adesão ou não dos usuários cadastrados na ESF se reflete no modo como os ACS são recebidos nos domicílios, como pôde ser percebido na observação das VD. As famílias que utilizam a ESF com maior frequência convidam os ACS para conversar sobre questões particulares, e aquelas que pouco utilizam, recebem os ACS para a realização da VD do lado de fora da casa.

O contato com o cotidiano das pessoas possibilita ao ACS vivenciar os problemas específicos de saúde da sua área de atuação, conhecer o modo de vida da população e contribuir para o processo de descentralização das informações. Cohn, Nakamura \& Cohn ressaltam que os ACS estão inseridos em uma dinâmica singular, visto que constituem lócus de interseção entre os domínios público e privado da vida social, "atuando como uma 'dobradiça' entre o público, de onde atua, e o privado de onde se origina por princípio, já que deve ser membro da comunidade"6(2).

A relação de vínculo criado com a comunidade foi citada por todas as ACS entrevistados como forma de facilitar o seu trabalho. Houve, ainda, quem evocasse a condição de morador como facilitadora da aproximação com as famílias. Desta forma, ao serem solicitados para 'bater papo' e tratar de assuntos da vida privada, da casa e do bairro, estabeleceram uma rede de informações sobre os acontecimentos locais e familiares.

Entretanto, se o fato de o ACS ser morador da comunidade contribui para que haja confiança nele para entrar nas residências, por outro lado, muitas vezes ele não é visto como profissional de saúde, por não ter a mesma formação técnica. Em situações que envolvem maior privacidade, também pode haver desconfiança dos usuários em relação à publicização de informações privadas, como destaca um ACS:

[...] não querem que você entre em casa. Não querem que você saiba do problema, por você ser vizinha. Pensa, assim, que a gente não tem a ética, né?! Não é?! E não tem coragem de desabafar com a gente. (ACS6).
A casa, em oposição à rua, constitui-se, no espaço da intimidade, como um lugar de segurança. A separação (designação) dos espaços domiciliares que podem ser acessados pelo visitante (no caso, o ACS) demostra o grau de intimidade que ele compartilha com a família. Para Da Matta, a rua é o lugar do anonimato, do impessoal, onde não há espaço para elos mais especializados; a casa, por sua vez, é o recanto da cordialidade, das relações mais íntimas e de confiança ${ }^{15}$.

O local de realização das VD variou muito: por vezes, a casa esteve aberta, com convite para sentar-se à mesa e tomar café; em outras ocasiões, ocorreu na varanda, ou com o portão entreaberto. Quando a VD era realizada dentro da casa, principalmente na sala e na cozinha, pareceu haver um grau de intimidade maior entre a família e o ACS, o que variou também de acordo com a facilidade das ACS para dialogar com as famílias sobre assuntos da comunidade e assuntos que 'escapam ao objetivo da VD'.

Cabe, então, problematizar as concepções dos ACS sobre suas próprias atribuições e sobre os objetivos da VD, considerando que o 'vínculo' se constrói por processos que se desenvolvem para além do espaço físico no qual a VD ocorre, e pode estar associado ao tipo de relação (mais ou menos assimétrica) que se estabelece entre o ACS e a população.

\section{As atribuições dos ACS e suas con- cepções sobre as práticas de atenção à saúde}

A VD é concebida como principal instrumento de trabalho do ACS, a quem compete realizar, no mínimo, uma visita mensal a cada família residente na sua microárea de abrangência, variando de acordo com a demanda da família.

Os ACS organizam seu trabalho observando certo 'cronograma', copiando um modelo já tradicional no processo de trabalho em saúde, que classifica os tipos de visitas como: visita de rotina a hipertenso, visita para conferir cartão de vacinação, busca ativa, cadastramento de usuários etc. A adoção de um aparente 
protocolo de visitas evidencia um recorte programático em detrimento do critério de necessidade dos usuários.

Há várias solicitações de VD por demanda espontânea, e quando ocorrem fora do horário de trabalho dos ACS, geram desconforto. Alguns ACS relataram o sentimento de serem constantemente 'vigiados' pelos moradores, mesmo em horários de lazer.

Durante as VD, são avaliadas as condições de habitação e de saneamento, oferecidas orientações sobre autocuidado e ações de educação em saúde, nas quais a noção de risco é abordada como forma de controle dos espaços e diminuição dos agravos. Aqui, o conceito de risco é agregado à microárea de atuação do ACS e das famílias, por meio de uma confluência de informações específicas sobre doenças crônicas, sobre o acompanhamento de gestantes, mulheres, crianças e sobre o dia a dia da equipe.

Uma das críticas ao enfoque quantitativista do risco refere-se ao fato de estabelecer uma entidade objetivável, autônoma sem considerar o contexto sociocultural no qual os indivíduos estão inscritos. A retórica do risco pode reafirmar conteúdos morais e conservadores. Ao redimensionar a compreensão de espaço e tempo, a biomedicina localiza em indivíduos sadios os seus possíveis riscos. A prevenção é acionada como forma de antever os agravos decorrentes da adoção de alguma conduta ou de suscetibilidades biológicas, através de diagnósticos precisos, e a fuga do risco se torna sinônimo de estilo de vida saudável16.

A promoção de estilos de vida saudáveis como forma de padronização do comportamento das famílias foi expressa em várias falas, principalmente quando tratou da adoção de mudança de hábitos alimentares. Embora haja juízo moral no entendimento do que seja uma 'boa alimentação', um dos ACS demostrou relacionar a 'má alimentação' não somente às escolhas individuais, entendendo que se trata também de um processo socioeconômico-cultural mais complexo.
A grande maioria da população tem a má alimentação, não porque querem, mas porque é mais barato comer errado. Não porque eles querem comer errado, é porque a condição deles não possibilita comer melhor. É mais barato você estar tomando um refrigerante que tomar um suco de laranja. (ACS9).

Os ACS evocam um saber técnico para sugerir estilos de vida a essa população, e a apropriação de um saber (no caso, o saber cientifico-médico) os coloca como propagadores de um saber 'certo'. Ao utilizarem, na fala, a expressão 'errado', fazem uma 'dicotomização' entre o 'certo' e o 'errado', tomando como o certo as práticas de alimentação saudável, tal como vêm sendo preconizadas pelas políticas de promoção à saúde. Não se pode negar a relação existente entre alimentação e adoecimento, no entanto, em nutrição, é necessário observar que o (re)estabelecimento da saúde não se dá apenas com a prescrição de alimentos ou dietas de forma a normatizar a alimentação ${ }^{17}$. Para Kraemer et al. ${ }^{17(1349)}$, tanto os profissionais de saúde quanto a mídia

utilizam essas recomendações para estabelecer um padrão de alimentação saudável idealizado para um indivíduo idealizado, materializado em um padrão legitimado socialmente.

O ACS incorpora um saber técnico e o coloca como balizador para julgar os comportamentos alimentares da população. Neste contexto, a perspectiva medicalizante ganha espaço e favorece o estabelecimento das relações assimétricas de poder, que desconsideram a subjetividade, os saberes e as práticas de cuidado do outro.

As reuniões realizadas com grupos de hipertensos, diabéticos e gestantes foram balizadas, tanto pelos ACS como pelos usuários, como instrumentos eficazes de orientação. No entanto, tais reuniões podem configurar-se como apenas mais alguns instrumentos de normatização e imposição de saber biomédico à comunidade. Mesmo não se tratando de ações violentas e arbitrárias que obriguem os indivíduos/comunidade a 
adotarem determinadas ações e comportamentos, tratam-se de estratégias revestidas do discurso científico, e acabam fazendo com que as pessoas sejam impelidas a cumprir o que está sendo estabelecido a partir do saber médico. Produzem novas formas de subjetividade daquilo que supostamente seria melhor para a coletividade ${ }^{\mathbf{1 8}}$. Ao dizer o que é certo e o que é errado de forma categórica, o profissional de saúde abre espaço para que seja gerada uma tutela na relação com os indivíduos/comunidade que incorporam o discurso de forma passiva:

Nas reuniões, é o que eles ensinam. Falando da alimentação, o que a gente pode fazer, o que não pode. Eles ensinam muito nas reuniões. (usuário3).

A atividade física é concebida como panaceia e o sedentarismo é abordado como doença que pode ser tratada no dia a dia, por meio de mudanças no estilo de vida. Para Castiel et al. ${ }^{16}$, a prescrição de estilos de vida saudáveis difunde um tipo de medicalização ainda mais perversa porque sub-replica a medicalização do cotidiano social. Torna-se, também, mais perversa quando a prática de atividade física é vendida como uma opção fácil, que pode ser feita em qualquer lugar:

[...] por mais que seja difícil, é tentar fazer cuidar com o que se tem, com o que se pode. É caminhada porque 'a rua está aí, liberada para todo mundo'. Não vai pagar, nem nada. Não custa dinheiro. (ACS7).

A observação das VD demostrou que a maioria das práticas realizadas pelos ACS procurou sugerir estilos de vida ditos saudáveis. Foram frequentes as recomendações para a adoção de atividades físicas, o controle do açúcar e para evitar o consumo de gordura.

Esse tipo de situação, sob o pretexto de autonomia em relação ao profissional de medicina, transfere para o indivíduo/comunidade a responsabilidade pelo domínio do saber médico.

Parece haver uma compreensão, por parte dos ACS, de que somente as ações educativas já seriam suficientes para modelar os comportamentos e valores da comunidade, na busca pela 'qualidade de vida'.

Foi possível perceber uma concepção amplamente compartilhada pelas ACS de que a ESF é quase sinônimo de PS e de prevenção de doença. Aspectos como qualidade de vida, atenção básica e educação em saúde foram recorrentes nas falas. Na concepção de alguns ACS entrevistados, a PS é concebida como sinônimo de prevenção à doença, e recorrentemente associada à vigilância e à fiscalização. Esta forma de conceber a prevenção em saúde passa a se manifestar na forma do biopoder, que supostamente se propõe à defesa da vida. Contudo, mantém um carácter disciplinador ao pontuar etapas, ciclos, espaços e comportamentos ditos adequados em prol de objetivos definidos e metas a serem atingidas através da mudança de conduta e do controle da população ${ }^{18}$.

Expressões como 'ter que ficar no pé' são frequentes e indicam uma perspectiva de que as atribuições dos ACS implicam em mecanismos de controle sobre o outro. A responsabilização individual como forma de controle de um agente público (no caso, o ACS) sobre a vida privada pode se expressar na culpabilização pelo adoecimento, sem considerar o contexto e as relações em que esses sujeitos estão inseridos. Neste processo, o discurso sobre autocuidado assume conotações específicas e compõe argumentos que sustentam determinadas estratégias de controle e esvaziam a subjetividade. Desta forma, recai sobre os indivíduos a responsabilidade principal e, por vezes, única de enfrentar os riscos que são socialmente gerados ${ }^{3}$.

Nespoli19(63) observa que, dado o seu caráter altamente prescritivo, a ESF pode estar atuando como um dispositivo regulatório nos territórios, como uma "estratégia política de expansão da medicalização dos corpos", onde a tática do 'quadriculamento' (definição de áreas, microáreas e domicílio) possibilita a disciplina dos indivíduos e o governo da população.

Uma perspectiva de PS que reforça a ideia de responsabilidade pessoal pode envolver primordialmente a noção de dever ou obrigação. 
Caberia ao indivíduo o principal poder de agência, sendo ele o principal responsável por sua situação de saúde-doença.

No entanto, os ACS também demonstraram grande desconforto em praticar a vigilância epidemiológica, principalmente quando foram obrigados a vistoriar os quintais das residências. Além disso, alguns ACS entrevistados sinalizaram a compreensão de elementos do contexto de vida da população e o entendimento da ESF como forma de atender integralmente ao usuário.

[...] promover a saúde é promover como um todo, né?! Não só o lado biológico, no quesito da doença, mas também a coisa social, o lado financeiro mesmo. Olhar como um todo aquela comunidade, pra 'tá lá, dando resolubilidade, tanto na questão socioeconômica como na questão biológica [...] tem que ter um olhar amplo, para enxergar o que numa consulta médica não se vê. (ACS9).

Ainda assim, o 'olhar amplo' pode vir acompanhado de uma perspectiva mais ampla também de controle, ou seja, não é a abordagem mais ou menos ampliada do processo saúde-doença que 'garante' práticas menos controladoras ou relações menos assimétricas.

No entanto, cabe considerar que, se por um lado a vigilância e a fiscalização são concebidas por esses ACS como suas atribuições, esse processo não se dá sem que haja algumas tensões. Se os ACS são agentes públicos, cabe considerar que essas atribuições são partes de estratégias de 'governamentalidade' desenhadas nas diversas esferas do poder público em que esses agentes se inserem, e que, portanto, influenciam suas concepções e práticas. Ainda assim, esses mesmos ACS, como sujeitos com autonomia relativa, podem reconstruir essas atribuições dos agentes públicos e reconfigurar suas práticas em seu cotidiano de trabalho. Uma hipótese aqui levantada é a de que essa reconfiguração pode reforçar, ou não, as assimetrias de poder nas relações que se estabelecem entre os ACS e a população, em função das abordagens mais ou menos dialógicas construídas por esses agentes no âmbito da VD.

\section{Práticas de atenção em saúde e (as) simetria nas relações entre agentes comunitários e população atendida}

A assimetria nas relações entre profissionais e usuários se configura na apropriação de questões/informações da vida privada do indivíduo, buscando uma normatização expressa nas tentativas de mudanças de hábitos e comportamentos, na prescrição de 'estilos de vida'. Neste cenário, destaca-se a imposição do 'saber-poder'. O imaginário que a população tem do profissional de saúde faz com que o indivíduo fique em uma condição de receptor passivo de orientação, normas e regras.

O perfil comunitário do ACS o coloca em uma relação de 'saber-poder' singular dentro da ESF, pois este, por residir na mesma comunidade que as famílias atendidas, compartilha os mesmos saberes com a população, mas, por outro lado, tem evocado o seu perfil de 'ser da saúde'. Neste encontro de saberes, parece que o prevalente é o segundo, ou seja, ao ACS é outorgado o potencial de ser portador de um saber mais técnico, e, neste sentido, 'mais correto' na sua percepção.

Por serem simultaneamente integrantes dos serviços de saúde e da comunidade, os ACS situam-se na 'fronteira da biopolítica do Estado', o que pode afetar as práticas de controle e as características da relação que estabelecem com a população ${ }^{20}$. Neste sentido, a possibilidade de construção de relações menos assimétricas é identificada nas situações em que os ACS valorizam a escuta e a conversa com o usuário e, neste contexto, até esquecem que estão trabalhando ${ }^{4}$. A conversa tem dimensão comunicacional e educativa, como parte nobre da técnica, complementando a clínica e a ampliação da qualidade do registro do paciente; 0 acolhimento requer que o trabalhador utilize seu saber para a construção de respostas às necessidades dos usuários ${ }^{\mathbf{4}, 21}$.

ACS entrevistados indicaram, como uma de suas principais atribuições, ouvir as demandas e as queixas da população, o que corresponde ao entendimento do usuário, que geralmente 
associa paciência na escuta à qualidade no atendimento. A horizontalidade da conversa tem importante efeito para diminuir as tensões que envolvem o cuidado à saúde 4 .

Quanto à troca de informações entre os profissionais da equipe, Fortes \& Spinett ${ }^{22(1330)}$ esclarecem que, embora necessária, é preciso que haja o zelo de limitar-se àquelas estritamente necessárias para o cuidado em saúde, e as informações privativas devem ser mediadas pelos profissionais de saúde, "que estabeleceriam, casa a casa, seus limites".

Franco e Merhy ${ }^{23}$, por outro lado, argumentam que, na VD, pode estar embutido o perigo da excessiva intromissão do Estado na vida das pessoas, limitando sobremaneira seu grau de privacidade e liberdade. Neste sentido, são evidenciados alguns conflitos em torno das equipes da ESF, a partir das relações estabelecidas entre a equipe, a comunidade e o ACS, uma vez que este detém um saber sanitário referente à esfera privada familiar - que nem sempre é de conhecimento dos demais integrantes das equipes -, o que lhe confere certo poder.

A forma como é conduzida a orientação em saúde indica que, por vezes, o ACS, na tentativa de intervir na melhoria da situação de saúde do usuário, opta por uma prática prescritiva e medicalizante ao dizer 'você tem que fazer'. Este tipo de postura reproduz visões moralizantes que permeiam os serviços de saúde, agem como produtoras do comum e operam de forma higienista na subjetividade ${ }^{4}$.

Observou-se uma desqualificação do usuário, sendo este 'o desprovido de conhecimento', justificando-se a intervenção no seu cuidado, associada à perspectiva de que a principal função do ACS é informar as pessoas sobre como devem se cuidar:

A gente prega sobre alimentação saudável, mas há um distanciamento da pregação pr'a prática. É como se a gente 'tivesse rezando uma missa e fazendo diferente, né?! A gente sabe o que é saudável, mas come o que é errado. (ACS9).

O colonialismo no sentido empregado por
Santos ${ }^{24}$ foi percebido nas relações entre os usuários e os ACS nas três equipes estudados. As observações e as falas dos ACS demostram que eles possuem uma visão normalizada dos usuários, na qual todos necessitam se comportar da mesma maneira. Por vezes, o discurso dos ACS é balizado em rótulos que designam os usuários como 'hipertensos' ou 'diabéticos', consequentemente demandando-lhes um padrão específico de comportamento. Santos ${ }^{25(30)}$ assinala que "estamos tão habituados a conceber o conhecimento como um princípio de ordem sobre as coisas e sobre os outros", que se torna complicado reconhecer o outro na condição de sujeito.

O ACS, por sua vez, procura trabalhar com ações de PS para legitimar o seu trabalho. Entre os recursos que utiliza estão os prospectos educativos produzidos por outras redes de cuidado. Tendo em vista a complexidade das relações que são estabelecidas no contexto da VD, no qual há constantes jogos de poder, observaram-se nuances nas relações de poder entre os ACS e os usuários, por vezes, convivendo no mesmo espaço uma extrema imposição de um saber-poder capturado do conhecimento biomédico e a valorização da singularidade do indivíduo/família.

Ainda que considerando a verticalização das relações de poder passível de ocorrer no momento em que o ACS e os usuários se encontram no ambiente domiciliar, foi possível verificar a singularidade desse encontro, a intersubjetividade que propiciou a composição de afetos entre os ACS e os usuários. Para Castro-Silva et al. ${ }^{26(114)}$, a valorização de dimensões subjetivas "traz à tona mais singularidades para a humanização das pessoas e ajuda a corporificar os problemas sociais e políticos que vivenciamos".

Alguns exemplos da tentativa de promover o autocuidado são citados pelos ACS e observados em três visitas, em relação à administração de medicamentos a pessoas analfabetas ou com dificuldades de enxergar, quando arquitetam ferramentas que facilitam o autocuidado dessas pessoas. Em uma das VD, o ACS separou a medicação da usuária em caixas para que não houvesse confusão nos horários. 
Mattos ${ }^{27}$, ao destacar a necessidade de reconhecer que as práticas de cuidado não podem ser pautadas tão somente no conhecimento científico, propõe uma ética profissional que esteja baseada no imperativo moral de defesa da vida, onde haja exame constante de crenças e práticas.

O exercício da escuta como mediadora do diálogo pode diminuir as assimetrias de poder entre o usuário e o profissional, uma vez que o trabalhador de saúde que considera o seu saber como único válido pode desencadear uma relação de opressão. A revisão dos perfis de relação entre o trabalhador e os usuários pode contribuir para superar o colonialismo na direção da horizontalidade e a invasão cultural no sentido do atendimento integral que perceba o outro como portador de saberes.

Foi possível observar, em muitas situações durante as VD, que a intervenção dos ACS não se limita ao quesito saúde, mas abarca questões referentes ao convívio familiar, na vida privada, incluindo aspectos da subjetividade que contribuem para um atendimento integral.

\section{Conclusões}

O presente estudo buscou compreender o modo como às práticas de saúde são exercidas pelo ACS no âmbito da VD em Morrinhos, Montes Claros (MG).

Nesse contexto, a VD é entendida pelos ACS como uma forma de apreender a realidade das famílias, conhecer o ambiente onde vivem, servindo como instrumento de informação para a ESF sobre a família e de elo entre a UBS e a comunidade.

O 'fazer' do ACS é evocado para compreender os aspectos subjetivos do trabalho em saúde, e o saber dos demais profissionais da equipe é considerado um trabalho especializado. Assim, o papel do ACS estaria relacionado à função de 'intérprete' para a compreensão da realidade local e elo entre esta e a UBS.

Ainda assim, observou-se que o fato de 'ser da comunidade' não pareceu ser o maior norteador do trabalho dos ACS, pois eles passaram a fazer os mesmos tipos de prescrições que os demais profissionais de saúde, inclusive utilizando uma linguagem técnica do campo da saúde.

No seu cotidiano, o ACS vive uma situação singular ao se colocar nesses polos, porém não há contradição neste fato. A micropolítica na qual se insere é atravessada por lógicas próprias quando os sujeitos, em encontro com as famílias, agenciam diferentes formas de cuidar. Esta adaptação ganha contornos mais nítidos à proporção que se observa a implicação dos ACS com a produção de um cuidado-cuidador na VD. Isto se expressa pela capacidade de perceber a singularidade de cada família e desenvolver estratégias diferenciadas de cuidado, atendendo à singularidade dos usuários e seus problemas de saúde, em algumas situações.

Por fim, observou-se que as práticas de saúde exercidas pelos ACS mesclaram uma imposição de um saber e uma relação mais dialógica no contato com os usuários, embora não escapassem de um processo de medicalização. Em alguns momentos, a assimetria de poder estabelecida gerou tutela, ao não deixar que os indivíduos se expressassem na construção do cuidado; e em outros, não necessariamente opostos, percebeu-se que a subjetividade foi considerada na construção do cuidado.

\section{Colaboradores}

Santana VC (0000-0002-8705-9552)* contribuiu substancialmente para a redação do artigo; planejamento, análise e interpretação dos dados; realização de entrevistas semiestruturadas e observação de campo. Burlandy L (0000-0003-0875-6374)* contribuiu para a concepção, o planejamento, a análise e a interpretação dos dados; revisão crítica do conteúdo; e aprovação da versão final do manuscrito. Mattos RA (0000-0003-0256-7046)* contribuiu para a revisão crítica do conteúdo e a aprovação da versão final.
*Orcid (Open Researcher and Contributor ID). 


\section{Referências}

1. Lupton D. The Imperative of Health. Public Health and the regulated body, London: Sage 1995.

2. Castiel LD, Álvarez-Dardet C. A saúde persecutória: os limites da responsabilidade. Rio de Janeiro: Editora Fiocruz; 2007. 136 p.

3. Foucault M. Em defesa da sociedade: curso no Collège de France (1975-1976). São Paulo: Martins Fontes; 1999.

4. Saffer DA, Barone LR. Em busca do comum: o cuidado do agente comunitário de saúde mental. Physis. 2017; 27(3):813-833.

5. Kebian LVA, Pena DA, Ferreira VA, et al. As práticas de saúde de enfermeiros na visita domiciliar e a promoção da saúde. Rev. APS. 2012 jan-mar; 15(1):92-100.

6. Cohn A, Nakamura E, Cohn C. O Programa de Saúde da Família entre o público e o privado. In: Viana ALD, Elias PEM, Ibañez N, organizadores. Proteção social. Dilemas e desafios. São Paulo: Hucitec; 2005. p. 168-185.

7. Santos EM, Kirschbaum DIR. A trajetória histórica da visita domiciliar no Brasil: uma revisão bibliográfica. REE. 2008; 10(1):220-227.

8. Mattos, RA. Integralidade, trabalho, saúde e formação profissional: algumas reflexões críticas feitas com base na defesa de alguns valores. In: Matta GC, Lima JCF, organizadores. Estado, sociedade e formação profissional: contribuições e desafios em 20 anos de SUS. Rio de Janeiro: Fiocruz; 2010. p. 313-52.

9. Carvalho SR. Os múltiplos sentidos da categoria “empowerment" no Projeto de Promoção à Saúde. Cad. de Saúde Pública. 2004; 20(4):1088-1095.

10. Ferreira Neto JL, Kind L, Resende MCC, et al. Processos da construção da Política Nacional de Promoção da Saúde. Cad. Saúde Pública. 2013; 29(10):19772007.
11. Silva PFA, Baptista TWF. Os sentidos e disputas na construção da Política Nacional de Promoção da Saúde. Physis 2014; 24(2):441-465.

12. Teixeira CF. Promoção da saúde e SUS: um diálogo pertinente. In. Carmem FT, Solla JP. Modelo de atenção à saúde: promoção, vigilância e saúde da família. Salvador: Edufba, 2006. p. 85-108.

13. Mattos RA. Os sentidos da Integralidade: algumas reflexões acerca de valores que merecem ser definidos. In: Pinheiro R, Mattos RA, organizadores. Os sentidos da integralidade na atenção e no cuidado à saúde. Rio de Janeiro: Abrasco; 2001, p. 39-84.

14. Foucault M. Microfísica do poder. Rio de Janeiro: Graal; 1979.

15. Da Matta R. A casa e a rua: espaço, cidadania, mulher e morte no Brasil. São Paulo: Saraiva; 1984.

16. Castiel LD, Guilham MCR, Ferreira MC. Correndo o risco: uma introdução aos riscos da saúde. Rio de Janeiro: Fiocruz; 2010.

17. Kraemer FB, Prado SD, Ferreira FR, et al. O discurso sobre a alimentação saudável como estratégia de biopoder. Physis. 2014; 24(4): 1337-1360.

18. Mázaro LP, Bernardes AG, Coêlho AEL. Análise das Políticas Públicas de Prevenção e Promoção em Saúde sob um olhar foucaultiano. Polis e Psique. 2012; 1(1):171-196.

19. Nespoli G. Biopolíticas da Participação na saúde: O SUS e o Governo das Populações. In: Guizardi FL, Nespoli G, Cunha ML, organizadores. Políticas de Participação e Saúde. Rio de Janeiro: EPSJV; Recife: UFPE, 2014. p. 59-90.

20. Borges SAC, Duarte MJO. Surfando no controle: os lugares que os agentes comunitários ocupam na produção de saúde mental. Saúde em Debate. 2017; 41(114): 920-931. 
21. Silva Junior AG, Mascarenhas MTM. Avaliação da Atenção Básica sob a Ótica da Integralidade: Aspectos Conceituais e metodológicos. In: Pinheiro R, Matos RA, organizadores. Cuidados - As fronteiras da integralidade. São Paulo: Hucitec; Rio de Janeiro: Abrasco; 2004. p. 241-257.

22. Fortes PC, Spinett SR. O Agente Comunitário de Saúde e a Privacidade das Informações. Cad. Saúde Pública; 2004; 20(5):1328-1333.

23. Franco T, Merhy E. PSF: Contradições e novos desafios: In: Conferência Nacional de Saúde. [internet] [acesso em 2013 jan 5]. Disponível em: http://www. datasus.gov.br/cns/cns/.htm.

24. Santos BS. Para um novo senso comum: a ciência, o direito e a política na transição paradigmática. 7. ed. São Paulo: Cortez; 2009.
25. Santos BS. Renovar a teoria crítica e reinventar a emancipação social. São Paulo: Bomtempo; 2007.

26. Castro-Silva CR, Mendes R, Moraes RCP, et al. Participação social e a potência do agente comunitário de saúde. Psicol. Soc. 2014; 26(esp):113-123.

27. Mattos RA. A Responsabilidade intelectual e solidariedade: por uma ética profissional pautada pela integralidade. In: Pinheiro R, Mattos RA, organizadores. Trabalho em equipe sob o eixo da integralidade: valores, saberes e práticas. Rio de Janeiro: Abrasco; 2007. p. 129-141.

Recebido em 20/08/2018

Aprovado em 04/12/2018

Conflito de interesses: inexistente

Suporte financeiro: não houve 